\title{
Cronologia histórica de Santa Maria e do extinto município de São Martinho: 1787 - 1930
}

Fernanda Kieling Pedrazzi ${ }^{1}$

A cidade e o tempo: a história de Santa Maria, coração do Rio Grande do Sul, em três séculos a partir de 1787. Da crônica jornalística do dia-a-dia ao livro de comemoração: os textos da página do jornal diário veiculados no século XX são reunidos em um só lugar, compondo uma obra feita de pesquisa e retalhos de realidade. Estas são algumas das relações pelas quais transitam a obra Cronologia Histórica de Santa Maria e do Extinto Município de São Martinho: 1787 - 1930(Editora da UFSM, 2013), de Romeu Beltrão, publicada pela primeira vez em 1958, pela segunda em 1979 e em nova edição, em 2013, que ganhou notas explicativas que atualizam o texto.

Graças a um protocolo assinado no ano de 2012 pelos filhos do autor, Aécio Cesar e Ápio Cláudio, e pelo responsável pela Editora da UFSM, Honório Rosa Nascimento, na abertura da Feira do Livro daquele ano, que homenageava Romeu Beltrão (BRENNER, 2013), teve início o esforço empreendido pela equipe de edição e revisão ligada à Universidade Federal de Santa Maria (UFSM).

Do original de Romeu até nossos dias se vão 55 anos, porém permanece na cronologia por ele pensada o olhar do médico apaixonado por documentos e pelo estudo da história de sua cidade e das personagens que a povoam na Santa Maria que percorre os séculos XVIII, XIX e XX. A obra é um fio, diga-se de passagem, de ouro, para quem pesquisa a história de Santa Maria e deseja adentrar nos seus meandros para contextualizar seus estudos.

Além dos Prefácios e de um Proêmio, o texto de Beltrão tem "Considerações preliminares", as quais versam sobre aspectos gerais da obra havendo, ali, uma explicação a respeito do que ele chamou de "marco inicial", sobre a escolha do ano 1787 e a apresentação de "al-

\footnotetext{
${ }^{1}$ Doutoranda pelo Programa de Pós-Graduação em Letras da Universidade Federal de Santa Maria - UFSM. E-mail: fernanda.pedrazzi@gmail.com
} 
gumas datas históricas", desde 1515, que, segundo ele, tem em vista "situar devidamente as origens de Santa Maria” (BELTRÃO, 2013, p. 35).

O texto em si se apresenta, tal qual fora escrito pelo autor, como um destaque de fatos importantes referentes à história da cidade, com o ano, mês e, às vezes, com a precisão do dia. Esta cronologia, como o título salienta, desenrola-se a partir da visão de Romeu, desde a página 46, em 596 páginas, fazendo um registro dos 143 anos que ele focaliza.

O livro é uma forma de homenagear a cidade que, em 1958, data da publicação original, completava 100 anos. Nele não só figura a história de Santa Maria como também a de “São Martinho de Cima da Serra”, que no ano da publicação estava extinto como município (tendo existido enquanto municipalidade, em sua primeira fase, de 1876 a 1901). Esta incomum extinção terminou quando, em 1992, o local deixa de ser distrito de Santa Maria e tornase município novamente, então como São Martinho da Serra.

O primeiro dia retratado na obra de Beltrão é 15 de abril de 1787, um domingo, no qual a $1^{\text {a }}$ Subdivisão da Comissão Demarcadora de Limites da América Meridional chega ao Rincão de Santa Maria (BELTRÃO, 2013, p. 47). No texto, há uma descrição do local onde acampou tal agrupamento, espaço geográfico em que se localiza o Bairro Passo da Areia, em, então, terras de sesmaria compradas pelo Padre Ambrósio José de Freitas e que, segundo Beltrão (2013, p. 49) ficou conhecida como "Estância do Padre Ambrósio". Estes dados, e tantos outros que se seguem, são, sem dúvida, marcos da história santa-mariense os quais são imprescindíveis de serem revisados para quem se aventura a trilhar na direção da história.

Além de datas consideradas importantes para a cidade, também se recupera, na obra, dados genealógicos de famílias que viveram e passaram por Santa Maria sendo assim recomposta a história particular, com seus nomes e sobrenomes, e pública de Santa Maria. O autor já registrara, no Proêmio da $1^{\mathrm{a}}$ edição, que tinha "gosto pela pesquisa histórica e pelo estudo da história" da sua "terra natal". Sua cronologia se fez a partir da visita a locais como o Bispado de Santa Maria e arquivos, onde pode encontrar acervos como o de São Martinho e registros oficiais. Além disso, Romeu fez uma grande pesquisa em obras, revistas e jornais que consultou. Outra fonte importante são os amigos, os arquivos vivos de sua época.

A nova edição mantém as características do texto de Romeu, porém, a cada edição, a publicação cresceu, literalmente. Na primeira edição tinha-se 199 páginas, na segunda, 582, e na atual, com uma apresentação impecável, chega-se a 775 páginas. É importante salientar, no entanto, que o próprio Romeu Beltrão informa, no Prefácio à segunda edição, que apesar de 
ter incluído muitos acréscimos e ter feito ajustes em seu texto, "foram suprimidos assuntos da $1^{\mathrm{a}}$, como a transcrição das atas da Câmara Municipal de São Martinho e outros, que os leitores interessados encontrarão na primeira" (BELTRÃO, 2013, p. 25). Dessa forma, a cada edição um detalhe se destaca, tornando as três importantes e passíveis de serem lidas e estudadas.

A produção da obra, reeditada na UFSM, recebeu o apoio de uma grande equipe que trabalhou muito e agregou informações ao texto de Beltrão, com profissionalismo nos esclarecimentos e correções. Na orelha da edição de 2013, redigida por José Antonio Brenner, chama-se a atenção para as palavras do autor sobre a primeira edição da obra: "tem não poucas imperfeições", o que se traduz em um gesto de humildade intelectual.

A segunda edição foi uma revisão e ampliação feita pelo próprio Romeu, que faleceu sem publicá-la. Sua morte precoce, em 1977, com apenas 64 anos, não lhe permitiu ver sua obra reeditada, conforme desejava, porém sua vontade e "sugestão", expressa em um bilhete, fora respeitada e honrada pelos filhos.

A terceira edição traz inovações. Além da contribuição dos filhos, teve o apoio de instituições, o empenho de historiadores, professores e acadêmicos da UFSM e de amigos da família de Beltrão. Ao final do texto, a obra apresenta fotos da Santa Maria de outros tempos sob o nome "Fotografias históricas", espaço que reúne imagens que foram cedidas pelos filhos, Aécio e Ápio, pelo professor aposentado da UFSM e pesquisador da história da região, José Antonio Brenner e pela Casa de Memória Edmundo Cardoso, uma importante instituição de pesquisa local. Trata-se de uma contribuição enorme para quem tem na leitura da obra uma fonte de pesquisa.

Logo nas primeiras páginas, há uma primeira "Nota explicativa", assinada pelo coordenador de reedição, o professor Pedro Brum Santos, atual diretor do Centro de Artes e Letras (CAL) da UFSM, explicitando o processo que culminou com o volume. Neste texto ele salienta que houve "fidelidade à versão original" e o cuidado para "limitar ao máximo" aquilo que chamou de "interferências" (SANTOS, 2013, p. 6). De forma bastante direta, o professor demonstra a magnitude de reeditar esta "obra-chave do passado santa-mariense" ao lembrar que agora aqueles que a conheciam já podem "acessá-la novamente, depois de anos esgotada. A esses se somam novos leitores desta imprescindível tarefa de desvendar o passado" (SANTOS, 2013, p. 7).

Na sequência das páginas pré-textuais, está a "Apresentação" da obra, elaborada pela professora do Departamento de História do Centro de Ciências Sociais e Humanas (CCSH) da 
UFSM, Beatriz Teixeira Weber. Weber salienta, em riqueza de detalhes, a visão de Romeu sobre a história de Santa Maria e a forma como ele concebeu seu texto. Além disso, Beatriz renova a leitura, dá uma luz aos seus escritos e analisa a contribuição da reedição acreditando estimular "a reflexão constante que os habitantes locais devem ter sobre seu espaço de vida, sobre o passado e o presente" (WEBER, 2013, p. 9).

Em sua apresentação, Weber cita não apenas Beltrão como também um outro importante escritor da história da cidade, João Belém, informando que os autores tiveram atribuído a seus textos o título de "história oficial da cidade" o que a pesquisadora considera como possível dadas as "circunstâncias políticas e intelectuais do período e as filiações dos seus autores” (WEBER, 2013, p. 9-10). Em seu texto, a professora reflete sobre a formação de historiadores no Estado, a partir de 1950, como a contribuição de outros profissionais se deu, a partir de eruditos no interior do Rio Grande do Sul e de que forma o texto de Beltrão, para ela um memorialista, pode ser classificado: uma monografia histórica, segundo Marobin (1995) citado por Weber (2013, p.11).

Sobre as notas de rodapé que explicam dados do texto de Beltrão, estas são elaboradas por diversos autores e somam pelo menos 190 notas. Os colaboradores em notas da terceira edição são: José Antonio Brenner (sendo que este tem expressiva contribuição com a grande maioria delas, 157 notas explicativas no corpo do texto e mais cinco nas "Considerações preliminares"), Pedro Brum Santos (oito notas) e Vitor Biasoli (20 notas), que como Beatriz é professor do Departamento de História do CCSH da UFSM. Todos são identificados junto as notas por suas iniciais. Estes pequenos textos têm diferentes fontes, outros autores da história de Santa Maria e região, dicionários, explicações conjunturais, etc.

As referências, que incluem as pesquisas para a edição de 2013, contêm 154 sugestões de obras para pesquisa sobre a cidade de Santa Maria, de São Martinho da Serra e sobre a história do Rio Grande do Sul e do Brasil.

A geração atual, que não teve acesso aos textos da primeira e segunda edições por tratarem-se de publicações esgotadas, ganhou uma oportunidade de conhecer o conteúdo e a estrutura criada por Beltrão para expressar a história de Santa Maria e de recompor sua trajetória como pesquisador. O resultado, pode ser visto no projeto gráfico e na diagramação que resultou não apenas em uma obra bela, como necessária. 


\section{Referências}

BELTRÃO, Romeu. 2013. Cronologia histórica de Santa Maria e do extinto município de São Martinho: 1787 - 1930. 3. ed. Santa Maria, RS: Ed. da UFSM. 776 p.

BRENNER, José Antonio. [Orelha]. 2013. In: BELTRÃO, Romeu. Cronologia histórica de Santa Maria e do extinto município de São Martinho: 1787 - 1930. 3. ed. Santa Maria, RS: Ed. da UFSM.

SANTOS, Pedro Brum. 2013. Nota explicativa. In: BELTRÃO, Romeu. Cronologia histórica de Santa Maria e do extinto município de São Martinho: 1787 - 1930. 3. ed. Santa Maria, RS: Ed. da UFSM. p. 5 - 7

WEBER, Beatriz Teixeira. Apresentação. 2013. In: BELTRÃO, Romeu. Cronologia histórica de Santa Maria e do extinto município de São Martinho: 1787 - 1930. 3. ed. Santa Maria, RS: Ed. da UFSM. p. 9 - 17 